\title{
Performance analysis and working fluid selection for geothermal energy-powered organic Rankine-vapor compression air conditioning
}

\author{
Xianbiao Bu ${ }^{1 *}$, Lingbao Wang ${ }^{1}$ and Huashan $\mathrm{Li}^{1,2}$
}

\author{
* Correspondence: \\ buxb@ms.giec.ac.cn \\ ${ }^{1}$ Key Laboratory of Renewable \\ Energy and Gas Hydrate, \\ Guangzhou Institute of Energy \\ Conversion, Chinese Academy of \\ Sciences, No.2, Nengyuan Rd, \\ Wushan, Tianhe District, Guangzhou \\ 510640, China \\ Full list of author information is \\ available at the end of the article
}

\begin{abstract}
Background: To utilize geothermal energy from hot springs, an organic Rankine cycle/vapor compression cycle (ORCNCC) system was employed for air conditioning and a thermodynamic model was developed.

Methods: Six working fluids, R123, R134a, R245fa, R600a, R600 and R290, were selected and compared in order to identify suitable working fluids which may yield high system efficiencies.

Results: The calculated results show that because of high system pressure for R290 and R134a, R600a is the more suitable working fluid for ORC in terms of expander size parameter, system efficiency and system pressure. In addition, R600a is also the most appropriate working fluid for VCC in terms of pressure ratio and coefficient of performance. R600 and R600a are more suitable working fluids for ORCNCC in terms of overall coefficient of performance, refrigerating capacity per unit mass flow rate and chilled water yield from per ton hot water.

Conclusions: In sum, R600a is the most suitable working fluid for ORCNCC through comprehensive comparison of ORC efficiency, expander size parameter, pressure ratio, coefficient of performance, system pressure and chilled water yield from per ton hot water for six different working fluids. However, the flammability of R600a should attract enough attention.
\end{abstract}

Keywords: Working fluid selection; Waste heat; Air conditioning; Hot spring; Organic Rankine-vapor compression; Expander

\section{Background}

There are a lot of hot springs in the world, many of which exceed $70^{\circ} \mathrm{C}$ (Lund et al. 2005, 2011), while the proper bath temperature at the hot spring hotel is generally in the range of $30^{\circ} \mathrm{C}$ to $50^{\circ} \mathrm{C}$, which causes the heat energy to be rejected to the atmosphere if the water temperature of the hot spring is higher than the bath temperature, resulting in greater waste of energy and the existence of thermal pollution in the surrounding environment. At the same time, most of the hot spring hotels need air conditioning. So, making use of these waste heats from hot springs released to the environment for air conditioning is of great significance.

At present, some effort has been devoted to the utilization of the vast amount of waste energy for refrigeration or air conditioning. Heat-operated absorption/adsorption systems

\section{Springer}

(c) 2013 Bu et al.; licensee Springer. This is an Open Access article distributed under the terms of the Creative Commons Attribution License (http://creativecommons.org/licenses/by/2.0), which permits unrestricted use, distribution, and reproduction in any medium, provided the original work is properly cited. 
can utilize waste heat for refrigeration or air conditioning (Lu et al. 2013; Luo et al. 2012). Srikhirin et al. (2001) described a number of research options of absorption refrigeration technology and provided a comparison of the various types of absorption refrigeration systems. Meunier (1998) claimed that solid sorption is very effective for low-grade cooling, not only for air conditioning but also for deep freezing. Wang et al. (2013) studied an absorption air-conditioning system driven by a low-grade geothermal heat source. Kairouani and Nehdi (2006) developed a novel combined compression-absorption refrigeration system assisted by geothermal energy. Davis and Wu (1997) used a finite-time thermodynamic approach to analyze a geothermal-powered low-temperature Rankine cycle for air conditioning. Rosiek and Batlles (2012) described a shallow geothermal system that was designed as an alternative to the cooling tower in a solar-assisted air-conditioning system installed in southern Spain. Lubis et al. (2011) carried out a thermodynamic analysis of a hybrid geothermal heat pump system. Kececiler et al. (2000) designed an absorption refrigeration system with geothermal energy and experimentally analyzed its performance.

Adsorption air-conditioning systems have the advantages of simple control, low initial investment and circulating expenditure, and less noise; however, the coefficient of performance is generally low. Because of sustainable development requirements, efficient refrigerators driven by low-grade thermal energy from different sources have received much more attention in recent years. Currently, the use of thermal energy to operate an organic Rankine cycle-vapor compression cycle (ORC/VCC) for refrigeration has become the subject of renewed interest and has been reported by several investigators. The ORC/VCC system converts waste heat into a cooling effect, which is accomplished at the site of the installation by using the organic Rankine cycle to generate the shaft work required to drive a vapor compression cycle. Aphornratana and Sriveerakul (2010) theoretically analyzed a combined Rankine vapor-compression refrigeration cycle powered by low-grade thermal energy. Wang et al. (2011a, b) introduced a novel thermally activated cooling concept - a combined cycle that couples an ORC and a VCC - and developed a prototype with a nominal cooling capacity of $5 \mathrm{~kW}$. Demierre et al. (2012) presented the development of an ORC-ORC prototype with HFC-134a as the working fluid and a heating power about $20 \mathrm{~kW}$ at the condenser. However, few people study the geothermal energy-powered ORC/VCC system for air conditioning, especially ORC/VCC system driven by waste heat from hot springs. In addition, the selection of working fluids has a great effect on the system efficiency and operation condition. Recently, many efforts have been made on the choice of working fluids and the performance analysis of the ORC (Invernizzi et al. 2007; Macchi and Perdichizzi 1981). Hung et al. (2010) investigated Rankine cycles using organic fluids as working fluids in converting low-grade energy and identified suitable working fluids which may yield high system efficiencies. Wang et al. (2012) presented a working fluid selection and parametric optimization using a multi-objective optimization model by simulated annealing algorithm. Guo et al. (2011) investigated the selection of working fluids for a novel low-temperature geothermal-powered ORC-based cogeneration system. Qiu (2012) compared eight mostly applied working fluids nowadays and gave preferable ranking by means of spinal point method. Wang et al. (2011c) analyzed the performance of different working fluids operating in specific regions using a thermodynamic model. Lakew and Bolland (2010) studied the performance of different working fluids to recover a low-temperature heat source. Stijepovic et al. (2012) explored the 
relationships between working fluid properties and ORC common economic and thermodynamic performance criteria from a theoretical and an analytical point of view.

In this paper, to utilize the vast amount of waste energy discharged from hot springs for air conditioning, the ORC/VCC system is employed and a thermodynamic model is developed. Six working fluids, including hydrochlorofluorocarbon (HCFC; e.g. R123), hydrofluorocarbons (HFCs; e.g. R134a and R245fa) and hydrocarbons (HCs; e.g. butane, isobutane and propane), are selected and evaluated to identify suitable working fluids which may yield high system efficiencies.

\section{Methods}

\section{System design and working fluid selection}

The system of ORC/VCC driven by waste energy from hot springs for air conditioning at hot spring hotels mainly consists of a geothermal water outlet, hot water pump, geothermal water inlet, generator, expander, compressor, evaporator, throttle valve, condenser, cooling water pump and working fluid pump, as shown in Figure 1. The working principle of this system is as follows: waste heats collected from hot springs provide energy to heat and vaporize a working fluid with low boiling point. Energy is extracted from this vapor in an expansion engine that is used to drive a vapor compressor for air conditioning. Afterwards, the fluid exiting the expander is condensed and pumped back to the generator where it is again vaporized. A vertical generator is used and countercurrent is applied in the generator to improve the system efficiency. That is, the hot water flows in the generator from top to bottom, and the working fluid flows from bottom to top in the generator. A water-cooled condenser is used in this system,

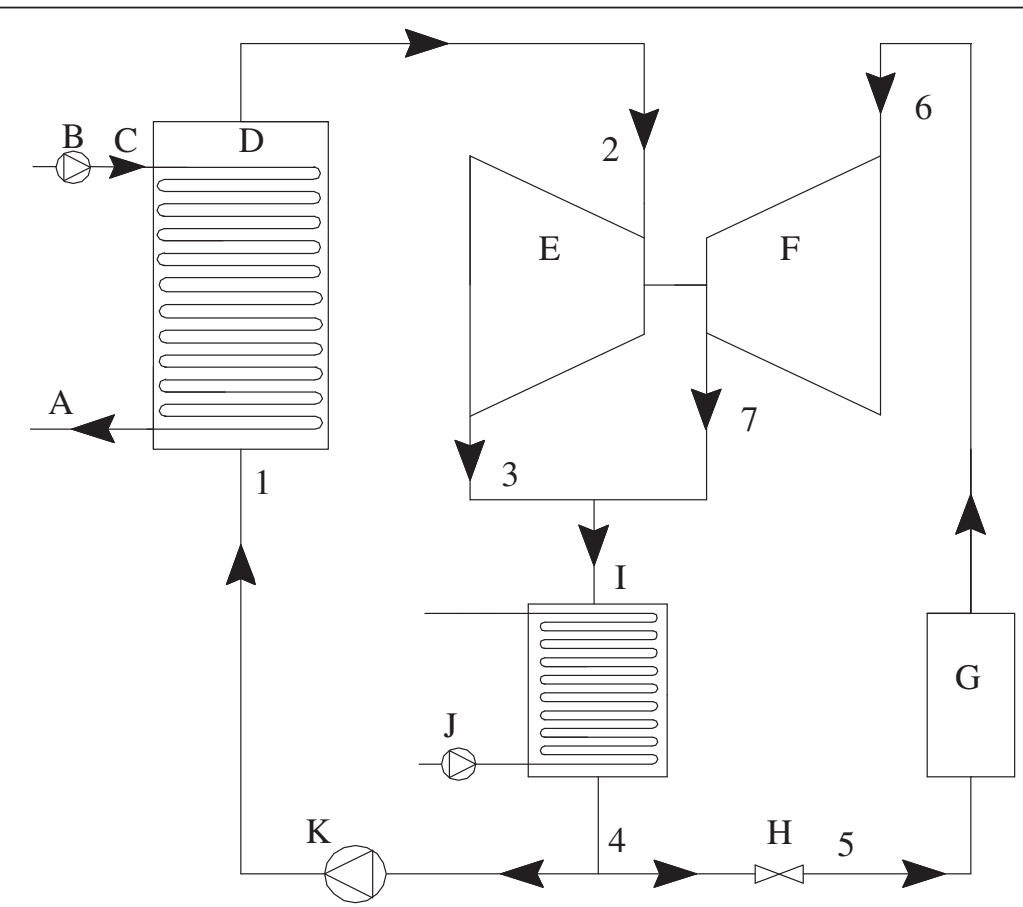

Figure 1 System schematic diagram. A, geothermal water outlet; $\mathbf{B}$, hot water pump; C, geothermal water inlet; $\mathbf{D}$, generator; $\mathbf{E}$, expander; $\mathbf{F}$, compressor; $\mathbf{G}$, evaporator; $\mathbf{H}$, throttle valve; I, condenser; J, cooling water pump; K, working fluid pump. 
which makes the system more compact and more powerful compared with the system cooled by air. The programmable logic controller, frequency converter and liquid level sensor are suggested to be adopted in the system to automatically control the liquid level of the working fluid in the generator and ensure high heat exchange efficiency in the generator. The temperature of waste heat from the hot spring and coolant usually varies along with the variation of ambient. To adapt the instability of heat source and coolant, the radial and axial flow expander is employed. To improve the drive efficiency, the compressor and the expander are directly coupled on the same shaft without gear and coupling. The same working fluid is used for both ORC and VCC to avoid the gas separation caused by leakage between them.

The common refrigerants HCFC (R123) and HFCs (R134a and R245fa) are selected as the working fluids for the ORC/VCC system. However, with increased environmental awareness, these refrigerants are now being regulated. It is well known that the HCs are environmentally friendly, non-toxic, chemically stable and highly soluble in conventional mineral oil. The only real argument against the application of HCs is flammability. So, the HCs, such as butane (R600), isobutene (R600a) and propane (R290), are also selected as the working fluids for the ORC/VCC system for air conditioning. The properties of six selected working fluids are shown in Table 1.

\section{Thermodynamic models}

To develop the thermodynamic models, the following assumptions are made:

1. Friction and heat losses in the ORC/VCC are negligible.

2. The power consumed by condensers for both ORC and VCC are negligible.

For ORC:

$$
\begin{aligned}
& W_{\text {exp }}=m_{\mathrm{p}}\left(h_{2}-h_{3 \mathrm{~s}}\right) \eta_{\text {exp }} \\
& W_{\text {pump }, \mathrm{w}}=m_{\mathrm{p}} \frac{\left(h_{1 \mathrm{~s}}-h_{4}\right)}{\eta_{\text {pump }, \mathrm{w}}} \\
& Q_{\text {boi }}=m_{\mathrm{p}}\left(h_{2}-h_{1}\right) \\
& W_{\text {net }}=W_{\text {exp }}-W_{\text {pump }, \mathrm{w}}
\end{aligned}
$$

Table 1 Properties of working fluids

\begin{tabular}{lcccc}
\hline Substance & $\begin{array}{c}\text { Molecular mass } \\
(\mathbf{g} / \mathbf{m o l})\end{array}$ & $\begin{array}{c}\boldsymbol{T}_{\text {crit }} \\
\left({ }^{\circ} \mathbf{C}\right)\end{array}$ & ODP & $\begin{array}{c}\text { GWP } \\
\text { (100 years) }\end{array}$ \\
\hline R290 & 44.10 & 96.68 & 0 & 3 \\
R600 & 58.13 & 151.98 & 0 & 20 \\
R600a & 58.13 & 134.67 & 0 & 20 \\
R123 & 152.93 & 183.68 & 0.012 & 76 \\
R245fa & 134 & 154.05 & 0 & 820 \\
R134a & 102.03 & 101.1 & 0 & 1,320 \\
\hline
\end{tabular}

ODP ozone depletion potential, relative to $\mathrm{R} 11$, GWP global warming potential, relative to $\mathrm{CO}_{2}$. 


$$
\begin{aligned}
& \eta_{\mathrm{p}}=\frac{W_{\text {net }}}{Q_{\text {boi }}} \\
& T_{\text {boi }}=\sqrt{T_{\mathrm{h}} T_{\mathrm{c}}} \\
& \mathrm{WRm}=\frac{W_{\text {net }}}{m_{\mathrm{p}}}=\left(h_{2}-h_{3 \mathrm{~s}}\right) \eta_{\text {exp }}-\frac{\left(h_{1 \mathrm{~s}}-h_{4}\right)}{\eta_{\mathrm{pump}, \mathrm{w}}} \\
& \mathrm{VFR}=\frac{V_{3}}{V_{2}} \\
& \mathrm{SP}=\frac{\sqrt{V_{3}}}{\sqrt[4]{1,000\left(h_{2}-h_{3 \mathrm{~s}}\right)}}
\end{aligned}
$$

For VCC:

$$
\begin{aligned}
& W_{\text {com }}=W_{\text {exp }} \\
& Q_{\text {eva }}=m_{\mathrm{ic}}\left(h_{6}-h_{5}\right) \\
& W_{\text {com }}=m_{\mathrm{ic}} \frac{\left(h_{7 \mathrm{~s}}-h_{6}\right)}{\eta_{\mathrm{com}}} \\
& \mathrm{COP}_{\mathrm{c}}=\frac{Q_{\text {eva }}}{W_{\text {com }}} \\
& \mathrm{PR}=\frac{P_{7}}{P_{6}} \\
& \mathrm{CRPR}=\frac{\mathrm{COP}_{\mathrm{c}}}{\mathrm{PR}}
\end{aligned}
$$

The overall performance of ORC/VCC is defined as follows:

$$
\begin{aligned}
& \mathrm{COP}_{\mathrm{s}}=\eta_{\mathrm{p}} \mathrm{COP}_{\mathrm{c}} \\
& m_{\mathrm{N}}=\frac{Q_{\mathrm{eva}}}{\mathrm{Cp}\left(T_{\mathrm{N} 1}-T_{\mathrm{N} 2}\right)} \\
& N=\frac{m_{\mathrm{N}}}{m_{\mathrm{h}}} \times 1,000 \\
& \mathrm{CPRm}_{\mathrm{A}}=\frac{Q_{\mathrm{eva}}}{m_{\mathrm{p}}+m_{\mathrm{ic}}}
\end{aligned}
$$

\section{Results and discussions}

Considering the temperature difference of hot water from hot springs at different places and the temperature variation of coolant in different seasons and places, the temperature of hot water at the generator inlet, $T_{\mathrm{h}}$, is in the range of $70^{\circ} \mathrm{C}$ to $95^{\circ} \mathrm{C}$, and the condensation temperature is respectively equal to $35^{\circ} \mathrm{C}, 40^{\circ} \mathrm{C}$ and $45^{\circ} \mathrm{C}$. For the sake of simplification, the mass flow rate of the working fluid for ORC is $1 \mathrm{~kg} / \mathrm{s}$. The evaporation temperature is $5^{\circ} \mathrm{C}$ and remains invariable, and the chilled water temperature at the evaporator inlet and outlet is, respectively, $14^{\circ} \mathrm{C}$ and $7^{\circ} \mathrm{C}$. The isentropic efficiencies for the expander, compressor and working fluid pump are 0.85, 0.8 and 0.9, respectively. 


\section{Effect of working fluid types on ORC}

In Figures 2, 3, 4, and 5, the condensation temperature is $40^{\circ} \mathrm{C}$.

The temperature of hot water from hot springs varies according to the season and weather, leading to the temperature variation of hot water at the generator inlet. As a result, the generation temperature $T_{\mathrm{boi}}$ varies with the variation of $T_{\mathrm{h}}$. Figure 2 exhibits $\eta_{\mathrm{p}}$ for different working fluids as a function of $T_{\mathrm{h}}$. It is obvious from Figure 2 that for all working fluids, $\eta_{\mathrm{p}}$ depends largely on $T_{\mathrm{h}}$ and it increases with the increase of $T_{\mathrm{h}}$. R290 has the maximum $\eta_{\mathrm{p}}$ compared with the five other working fluids for all heat source temperatures, followed by R134a, and R123 has the minimum $\eta_{\mathrm{p}}$. Except R134a, $\eta_{\mathrm{p}}$ for HCs is higher than those for R123 and R245fa. $\eta_{\mathrm{p}}$ is 6.75\%, 6.57\%, 5.92\%, 5.75\%, $5.62 \%$ and $5.53 \%$ for working fluids R290, R134a, R600a, R600, R245fa and R123, respectively, at $T_{\mathrm{h}}=85^{\circ} \mathrm{C}$, signifying that $\eta_{\mathrm{p}}$ for $\mathrm{R} 290$ is 1.22 times higher than that for R123.

Figure 3 illustrates the variation of WRm with $T_{\mathrm{h}}$. WRm is defined as the ratio of $W_{\text {net }}$ to $m_{\mathrm{p}}$, reflecting the power capability of the working fluid per unit mass flow rate. Observing the profiles from Figure 3 for all working fluids, WRm increases with the increase of $T_{\mathrm{h}}$. This is due to the fact that the difference between $h_{2}$ and $h_{3 \mathrm{~s}}$ increases with increasing $T_{\mathrm{h}}$, while $h_{1 \mathrm{~s}}$ and $h_{4}$ remain unchanged when the condensation temperature is invariable, thus leading to the increase of WRm according to Equation 7. WRm for R290 and R600 are almost the same and they are the maximum among the six working fluids. WRm for HCs is higher than those for R123, R245fa and R134a as shown in Figure 3. WRm for R123 and R600 is, respectively, 9.83 and $21.58 \mathrm{~kW} \mathrm{~s} / \mathrm{kg}$ at $T_{\mathrm{h}}=85^{\circ} \mathrm{C}$, the former being about 2.2 times as high as the latter.

VFR as a function of $T_{\mathrm{h}}$ is plotted and presented in Figure 4. VFR is defined as the specific volume variation across the expander in an isentropic process, which accounts for the effect of the compressibility through the expansion. As it is seen from Figure 4, with the increase of $T_{\mathrm{h}}$, VFR for all working fluids increases. R123 has the highest VFR,

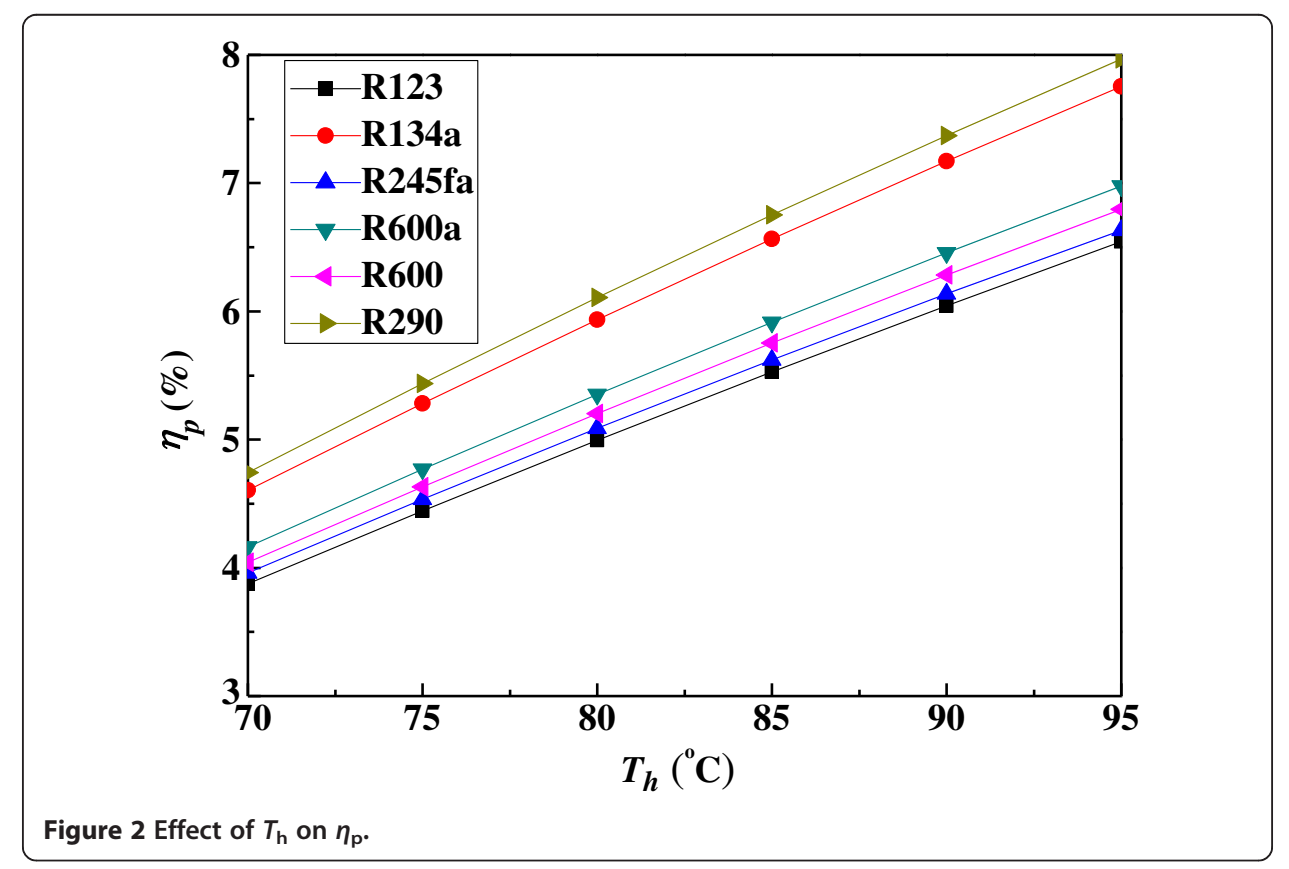




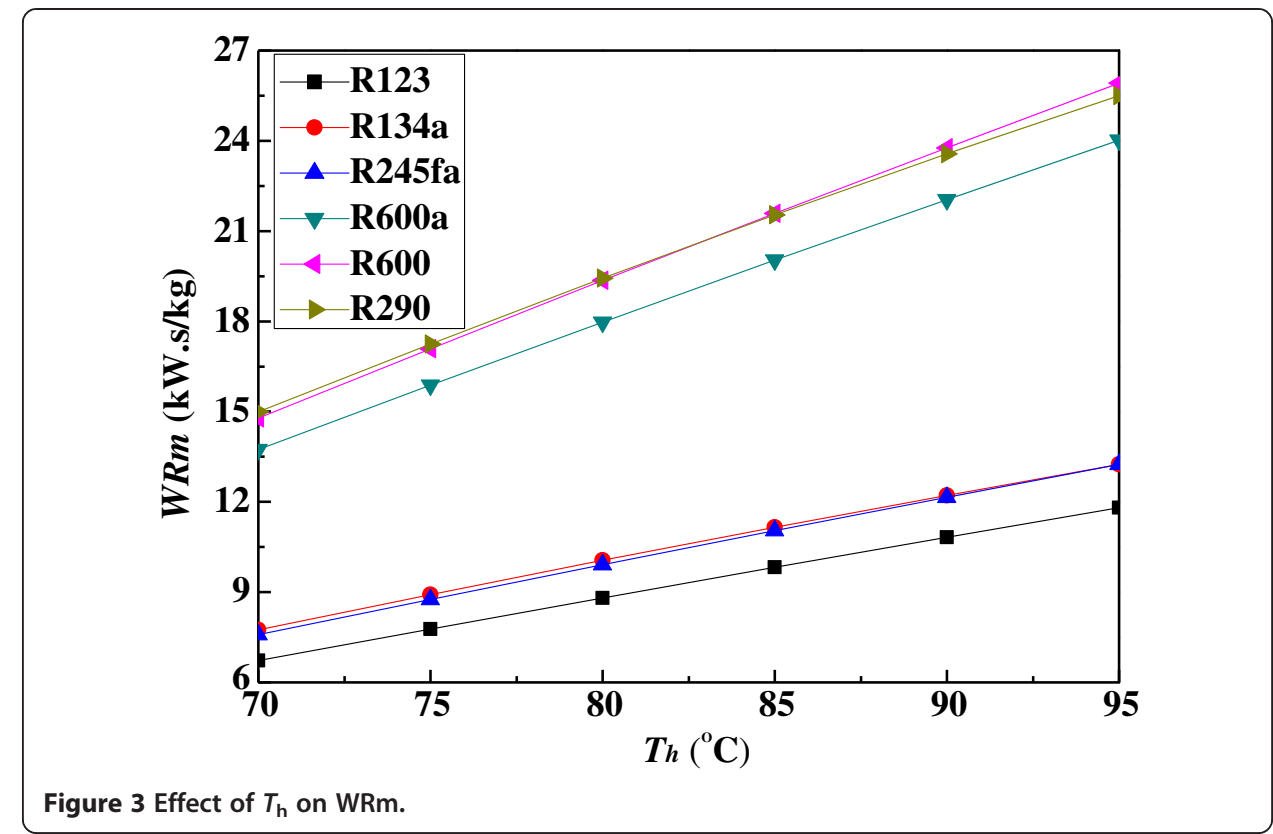

while R290 has the lowest VFR. Observing the profiles from Figures 2 and 4, a conclusion can easily be drawn that low VFR leads to high $\eta_{\mathrm{p}}$. This conclusion is consistent with that obtained by Macchi and Perdichizzi (1981). According to Macchi and Perdichizzi (1981), lower values of VFR deliver higher turbine efficiency. Moreover, Invernizzi et al. (2007) stated that in order to achieve a turbine efficiency higher than $80 \%$, the VFR should be lower than 50. In this study, VFR for all working fluids is less than 2.2; thus, expander efficiency higher than $80 \%$ can be achieved.

Figure 5 shows the expander size parameter SP plotted as a function of $T_{\mathrm{h}}$. The expander size parameter given by Equation 9 is an indicator of expander size, and it is

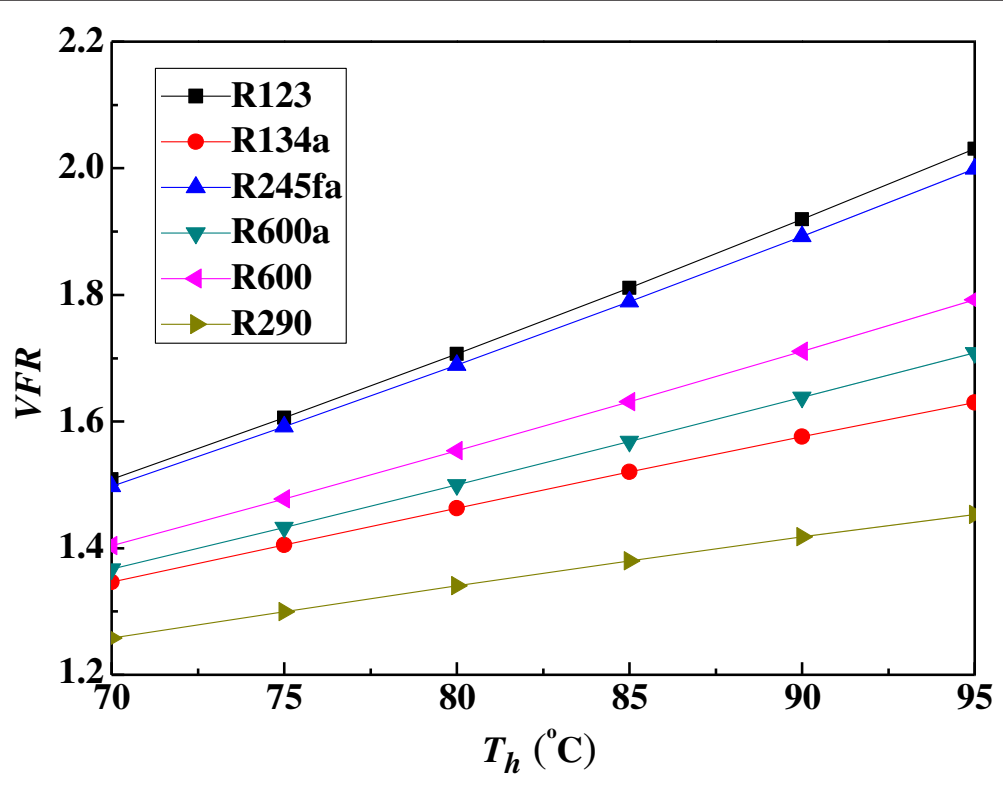

Figure 4 Effect of $T_{\mathrm{h}}$ on VFR. 


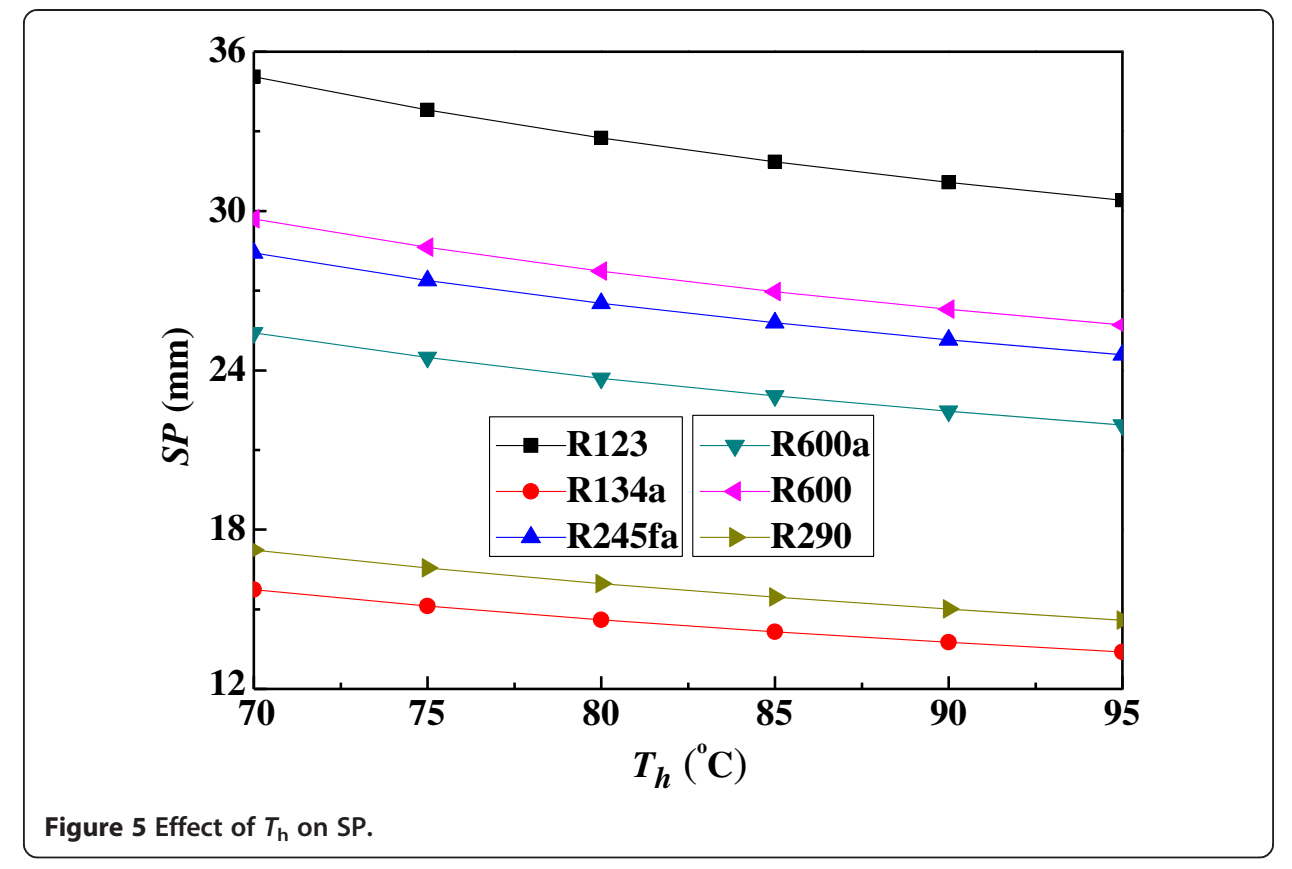

proportional to the actual expander size (Lakew and Bolland 2010; Stijepovic et al. 2012). As shown in Figure 5, SP decreases with increasing $T_{\mathrm{h}}$ for all working fluids, and this is attributed to the fact that higher $T_{\mathrm{h}}$ leads to higher enthalpy drop between the expander inlet and outlet as well as higher $\eta_{\mathrm{p}}$ and thus less SP according to Equation 9. As it is seen from Figure 5, SP is lowest for R134a for all heat source temperatures compared with the five other working fluids and R290 is the second lowest. This is likely due to the fact that compared with the four other working fluids, R134a and R290 have higher pressure and thus higher density at the expander outlet, resulting in lower $V_{3}$ and thus lower SP according to Equation 9.

Based on the above discussion, it is thus clear that in terms of $\eta_{\mathrm{p}}$ and SP, R290 and R134a are more suitable working fluids for ORC for recovering low-grade waste heat. However, the system pressures for working fluids R290 and R134a are also high, reaching 2,116 and 1,682 $\mathrm{kPa}$, respectively, at $T_{\text {boi }}=60^{\circ} \mathrm{C}$, resulting in high system investment. Except R290 and R134a, R600a is superior to R600, R123 and R245fa in terms of $\eta_{\mathrm{p}}$ and SP. Moreover, the system pressures for R600a is also not high, reaching $868.3 \mathrm{kPa}$ at $T_{\mathrm{boi}}=60^{\circ} \mathrm{C}$. To sum up the above discussion, $\mathrm{R} 600 \mathrm{a}$ is the most suitable among the six selected working fluids for ORC for recovering low-grade waste heat in the temperature range of $70^{\circ} \mathrm{C}$ to $95^{\circ} \mathrm{C}$.

\section{Effect of working fluid types on VCC}

The condensation temperature varies with ambient. Table 2 shows the effects of $T_{\mathrm{c}}$ and working fluid types on $\mathrm{COP}_{\mathrm{c}}$, PR and CRPR. In Table $2, T_{\mathrm{h}}$ equals $85^{\circ} \mathrm{C}$. As shown in Table 2, $\mathrm{COP}_{\mathrm{c}}$, PR and CRPR depend largely on $T_{\mathrm{c}}, \mathrm{COP}_{\mathrm{c}}$ and CRPR decrease with $T_{\mathrm{c}}$, and PR increases with $T_{\mathrm{c}}$. This is due to the fact that when the pressure and temperature remain invariable at the compressor inlet, the increasing $T_{\mathrm{c}}$ leads to the increase of pressure and enthalpy at the compressor outlet and thus the increase of PR and the decrease of $\mathrm{COP}_{\mathrm{c}}$ as well as CRPR according to Equations 11 to 15 . 
Table 2 Performance of VCC with different $T_{c}$

\begin{tabular}{llllll}
\hline Fluid type & $\boldsymbol{T}_{\mathbf{c}}\left({ }^{\circ} \mathbf{C}\right)$ & COP $_{\mathbf{c}}$ & PR & CRPR & $\boldsymbol{N}(\mathbf{k g} / \mathbf{t})$ \\
\hline R123 & 35 & 6.41 & 3.20 & 2.00 & $1,366.7$ \\
R123 & 40 & 5.36 & 3.78 & 1.42 & 893.32 \\
R123 & 45 & 4.56 & 4.45 & 1.02 & 575.81 \\
R134a & 35 & 5.30 & 2.54 & 2.09 & $1,475.9$ \\
R134a & 40 & 4.46 & 2.91 & 1.53 & $1,005.8$ \\
R134a & 45 & 3.58 & 3.32 & 1.08 & 618.99 \\
R245fa & 35 & 6.10 & 3.20 & 1.91 & $1,364.8$ \\
R245fa & 40 & 5.05 & 3.78 & 1.34 & 887.59 \\
R245fa & 45 & 4.27 & 4.45 & 0.96 & 568.8 \\
R600a & 35 & 5.77 & 2.49 & 2.32 & $1,402.9$ \\
R600a & 40 & 4.76 & 2.85 & 1.67 & 911.84 \\
R600a & 45 & 3.99 & 3.24 & 1.23 & 583.79 \\
R600 & 35 & 6.03 & 2.64 & 2.28 & $1,385.8$ \\
R600 & 40 & 5.00 & 3.05 & 1.64 & 902.63 \\
R600 & 45 & 4.22 & 3.49 & 1.21 & 579.49 \\
R290 & 35 & 3.41 & 3.00 & 1.14 & $1,020.2$ \\
R290 & 35 & 2.87 & 3.37 & 0.85 & 689.69 \\
R290 & 40 & 2.43 & 3.78 & 0.64 & 455.06 \\
\hline
\end{tabular}

It is obvious from Table 2 that $\mathrm{R} 123$ has the maximum $\mathrm{COP}_{\mathrm{c}}$ while $\mathrm{R} 290$ has the minimum $\mathrm{COP}_{\mathrm{c}}$. PR for R123 and R245fa are almost the same and they are greater than those for the four other working fluids. PR for R600a is the lowest among the six selected working fluids. It is well known that working fluids with high $\mathrm{COP}_{\mathrm{c}}$ and low $\mathrm{PR}$ are suitable refrigerants for VCC. To evaluate working fluid refrigeration performance and the relationships between $\mathrm{COP}_{\mathrm{c}}$ and $\mathrm{PR}, \mathrm{CRPR}$ is hence defined as the ratio of $\mathrm{COP}_{c}$ to $\mathrm{PR}$, which is an indicator of working fluid refrigeration performance. Higher CRPR indicates better refrigeration performance for working fluids. R600a has the maximum CRPR compared with the five other working fluids, followed by R600, as shown in Table 2.

According to the comprehensive comparison of $\mathrm{COP}_{c}, \mathrm{PR}$ and $\mathrm{CRPR}$ for the six different working fluids, it is clear that R600a is the most suitable working fluid for VCC.

\section{Effect of working fluid types on ORC/VCC}

In Figures 6, 7, and 8, the condensation temperature is $40^{\circ} \mathrm{C}$.

Figure 6 illustrates the variation of $\mathrm{COP}_{\mathrm{s}}$ as a function of $T_{\mathrm{h}}$. In Figure 6 , with the increase of $T_{\mathrm{h}}, \mathrm{COP}_{\mathrm{s}}$ increases for all working fluids. $\mathrm{COP}_{\mathrm{s}}$ equals the product of $\eta_{\mathrm{p}}$ and $\mathrm{COP}_{\mathrm{c}} \cdot \eta_{\mathrm{p}}$ for R123 is the lowest among the six working fluids, as shown in Figure 2, and $\mathrm{COP}_{c}$ is however highest for R123 among the six working fluids in Table 2; as a result, the product of $\eta_{\mathrm{p}}$ and $\mathrm{COP}_{\mathrm{c}}$ is highest. As evident in Figure 6, R123 has the highest $\mathrm{COP}_{\mathrm{s}}$ and $\mathrm{R} 290$ has the lowest $\mathrm{COP}_{\mathrm{s}}$ for all heat source temperatures. Except $\mathrm{R} 290$, the differences between $\mathrm{COP}_{\mathrm{s}}$ for the five other working fluids are very small. For example, $\mathrm{COP}_{\mathrm{s}}$ is $26.76 \%, 26.45 \%, 26.01 \%, 25.72 \%$ and $25.47 \%$ for working fluids R123, R134a, R600, R245fa and R600a, respectively, at $T_{\mathrm{h}}=80^{\circ} \mathrm{C}$, and they respectively increase to $35.04 \%, 34.55 \%, 33.97 \%, 33.52 \%$ and $33.21 \%$ at $T_{\mathrm{h}}=95^{\circ} \mathrm{C}$. 


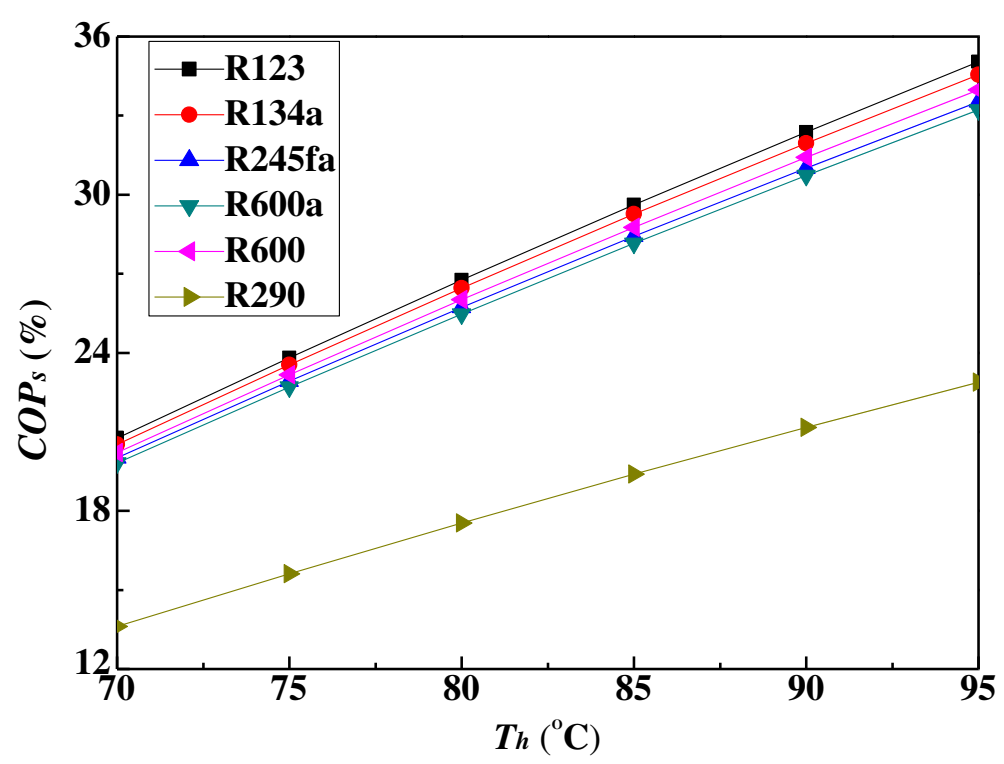

Figure 6 Effect of $T_{\mathrm{h}}$ on $\mathrm{COP}_{\mathrm{s}}$.

The effect of $T_{\mathrm{h}}$ on $\mathrm{CPRm}_{\mathrm{A}}$ is shown in Figure 7. CPRm $\mathrm{A}$ is defined as the ratio of $Q_{\text {eva }}$ to $\left(m_{\mathrm{p}}+m_{\mathrm{ic}}\right)$, which reflects the refrigerating capacity of the working fluid per unit mass flow rate. As evident in Figure 7, CPRm $\mathrm{A}$ increases with $T_{\mathrm{h}}$ for all working fluids. R600 and R600a have the highest and second highest $\mathrm{CPRm}_{\mathrm{A}} \cdot \mathrm{CPRm}_{\mathrm{A}}$ for $\mathrm{HCs}$ is higher than those for R123, R134a and R245fa. So, HCs of R290, R600 and R600a are more suitable working fluids for ORC/VCC compared with working fluids R123, R134a and R245fa.

$N$ as a function of $T_{\mathrm{h}}$ is plotted and presented in Figure 8 . Figure 8 shows that $N$ depends largely on $T_{\mathrm{h}}$ and it increases with $T_{\mathrm{h}}$ for all working fluids. R134a has the highest $N$ and R290 has the lowest $N$ for all heat source temperatures. Except R134a

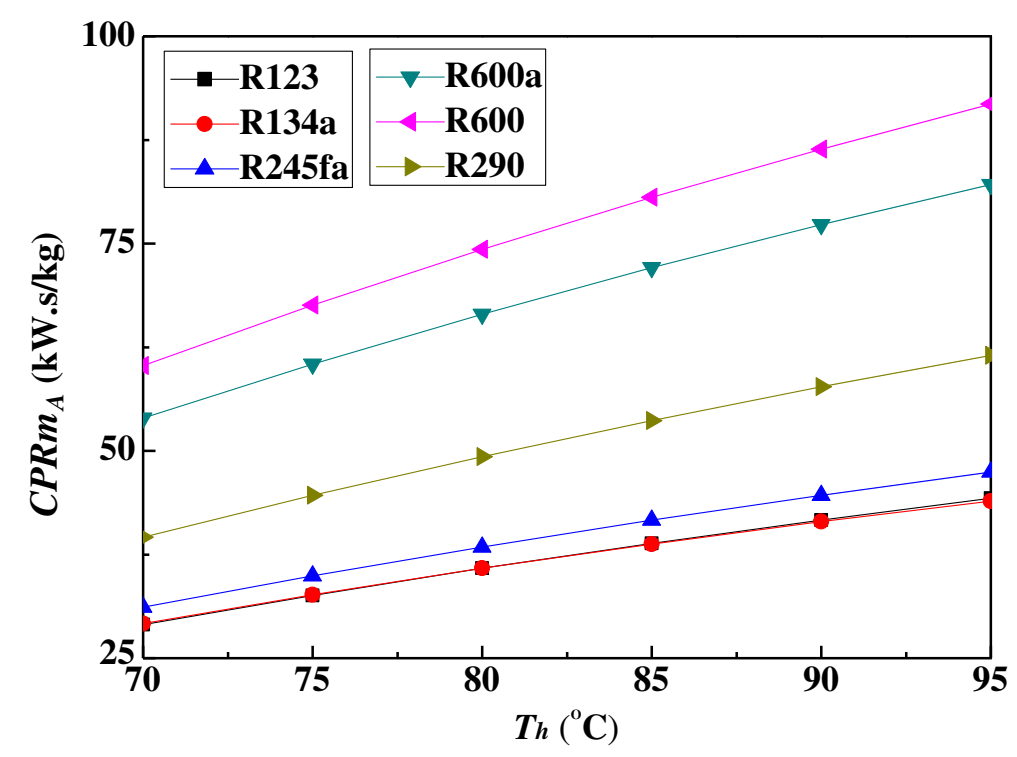

Figure 7 Effect of $T_{\mathrm{h}}$ on $\mathrm{CPRm}_{\mathrm{A}}$. 


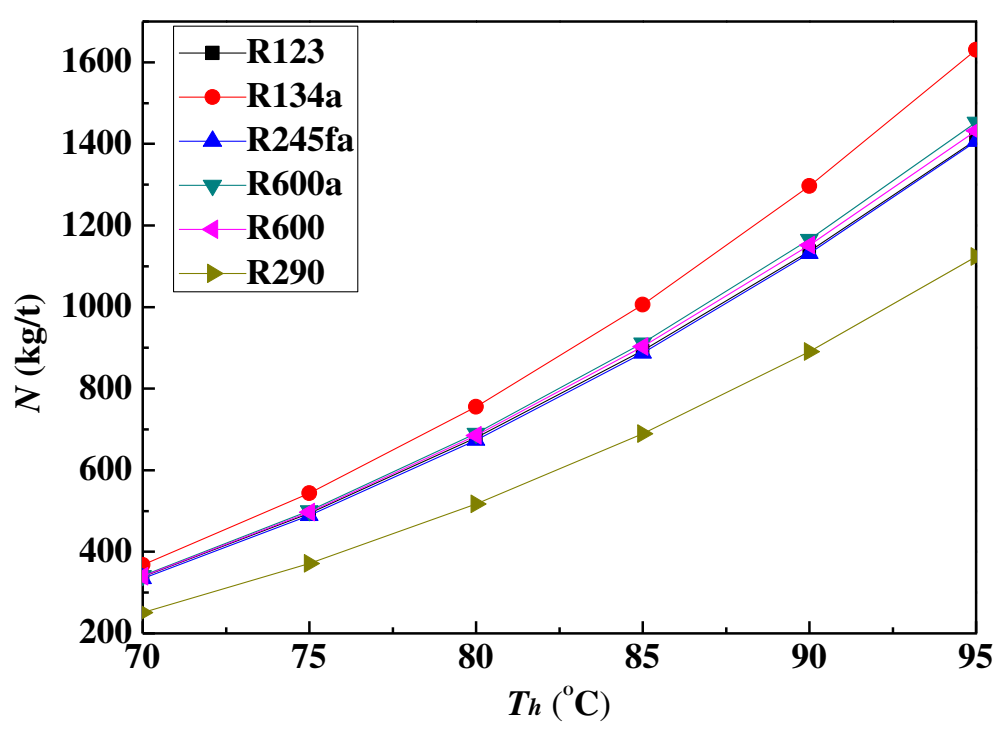

Figure 8 Effect of $T_{\mathrm{h}}$ on $N$.

and R290, the differences between $N$ for the four other working fluids are very small. For example, $N$ is 755.41, 690.22, 684.76, 679.39, 673.73 and $517.1 \mathrm{~kg} / \mathrm{t}$ for R134a, R600a, R600, R123, R245fa and R290, respectively, at $T_{\mathrm{h}}=80^{\circ} \mathrm{C}$, and they respectively increase to $1,409.8,1,630.4,1,406.5,1,453.4,1,432.1$ and $1,123.6 \mathrm{~kg} / \mathrm{t}$ at $T_{\mathrm{h}}=95^{\circ} \mathrm{C}$.

So, in terms of $\mathrm{COP}_{\mathrm{s}}$ and $N, \mathrm{R} 600$ and R600a are more suitable working fluids for ORC/VCC.

In addition, the condensation temperature has an important influence on $N$, as shown in Table 2. Taking R134a as an example, $N$ at $T_{\mathrm{c}}=35^{\circ} \mathrm{C}, 40^{\circ} \mathrm{C}$ and $45^{\circ} \mathrm{C}$ is, respectively, $1,475.9,1,005.8$ and $618.99 \mathrm{~kg} / \mathrm{t} . N$ at $T_{\mathrm{c}}=35^{\circ} \mathrm{C}$ is 1.47 times larger than that at $T_{\mathrm{c}}=40^{\circ} \mathrm{C}$ and is 2.38 times larger than that at $T_{\mathrm{c}}=45^{\circ} \mathrm{C}$, indicating that there is a great difference of cooling capability for ORC/VCC air-conditioning system with different condensation temperatures. The condensation temperature depends on the ambient temperature, heat exchanger area of the condenser and cooling water flow rate, while the cooling water flow rate influences the heat exchanger area of the condenser and the selection of cooling water pump and thus the system investment and payback period. Thus, the system performance and payback period should be comprehensively considered so as to decide the optimal condensation temperature during practical design.

In sum, R600a is the most suitable working fluid for ORC/VCC through the comprehensive comparison of $\eta_{\mathrm{p}}, \mathrm{SP}, \mathrm{COP}_{\mathrm{c}}, \mathrm{PR}, \mathrm{CRPR}, \mathrm{COP}_{\mathrm{s}}, \mathrm{CPRm}_{\mathrm{A}}, N$ and system pressure for the six different working fluids; however, the flammability of R600a should attract enough attention.

\section{Conclusions}

To efficiently utilize waste heat from hot springs for air conditioning at the hot spring hotel, the organic Rankine-vapor compression cycle system was employed and a thermodynamic model was developed. Six working fluids, R123, R134a, R245fa, R600a, R600 and R290, were selected and compared to identify suitable working fluids which may yield high system efficiencies. The calculated results show that in terms of $\eta_{\mathrm{p}}$ and 
SP, R290 and R134a are more suitable working fluids for ORC for recovering low-grade waste heat in the temperature range of $70^{\circ} \mathrm{C}$ to $95^{\circ} \mathrm{C}$. However, their system pressures are too high, resulting in high system investment. Except R290 and R134a, R600a is the more suitable working fluid for ORC in terms of ORC efficiency, expander size parameter and system pressure. R600a is the most appropriate working fluid for VCC in terms of PR, $\mathrm{COP}_{\mathrm{c}}$ and CRPR. In terms of $\mathrm{COP}_{\mathrm{s}}, \mathrm{CPRm}_{\mathrm{A}}$ and $N, \mathrm{HCs}$ of R600 and R600a are more suitable working fluids for ORC/VCC compared with working fluids R290, R123, R134a and R245fa. In sum, R600a is the most suitable working fluid for ORC/VCC through the comprehensive comparison of $\eta_{\mathrm{p}}$, SP, COP, PR, CRPR, COP , $\mathrm{CPRm}_{\mathrm{A}}, N$ and system pressure for the six different working fluids; however, the flammability of R600a should attract enough attention.

\section{Nomenclature}

$\mathrm{COP}_{\mathrm{c}}$ coefficient of performance for VCC

$\mathrm{COP}_{\mathrm{s}}$ overall coefficient of performance for ORC/VCC

$\mathrm{Cp}$ specific heat of chilled water $(\mathrm{kJ} /(\mathrm{kg} \mathrm{K}))$

$\mathrm{CPRm}_{\mathrm{A}}$ ratio of $Q_{\text {eva }}$ to overall mass flows of ORC/VCC

CRPR ratio of $\mathrm{COP}_{\mathrm{c}}$ to $\mathrm{PR}$

$h_{1}$ enthalpy at the working fluid pump outlet $(\mathrm{kJ} / \mathrm{kg})$

$h_{1 \mathrm{~s}}$ enthalpy at the working fluid pump outlet based on an isentropic process $(\mathrm{kJ} / \mathrm{kg})$

$h_{2}$ enthalpy at the expander inlet $(\mathrm{kJ} / \mathrm{kg})$

$h_{3 \mathrm{~s}}$ enthalpy at the expander outlet based on an isentropic process $(\mathrm{kJ} / \mathrm{kg})$

$h_{4}$ enthalpy at the working fluid pump inlet $(\mathrm{kJ} / \mathrm{kg})$

$h_{5}$ enthalpy at the evaporator inlet $(\mathrm{kJ} / \mathrm{kg})$

$h_{6}$ enthalpy at the evaporator outlet $(\mathrm{kJ} / \mathrm{kg})$

$h_{7 \mathrm{~s}}$ enthalpy at the compressor outlet based on an isentropic process $(\mathrm{kJ} / \mathrm{kg})$

$m_{\mathrm{h}}$ mass flow rate for hot water $(\mathrm{kg} / \mathrm{s})$

$m_{\mathrm{ic}}$ mass flow rate of the working fluid for $\mathrm{VCC}(\mathrm{kg} / \mathrm{s})$

$m_{\mathrm{N}}$ mass flow rate of chilled water $(\mathrm{kg} / \mathrm{s})$

$m_{\mathrm{p}}$ mass flow rate of the working fluid for ORC $(\mathrm{kg} / \mathrm{s})$

$N$ chilled water yield from per ton hot water $(\mathrm{kg} / \mathrm{t})$

$P_{6}$ pressure at the compressor inlet $(\mathrm{kPa})$

$P_{7}$ pressure at the compressor outlet $(\mathrm{kPa})$

PR pressure ratio between the compressor inlet and outlet

$Q_{\text {boi }}$ generator heat input $(\mathrm{kW})$

$Q_{\text {eva }}$ evaporator power for the ice maker $(\mathrm{kW})$

SP expander size parameter $(\mathrm{m})$

$T_{\text {boi }}$ generation temperature in the generator $\left({ }^{\circ} \mathrm{C}\right)$

$T_{\mathrm{c}}$ condensation temperature $\left({ }^{\circ} \mathrm{C}\right)$

$T_{\text {crit }}$ critical temperature $\left({ }^{\circ} \mathrm{C}\right)$

$T_{\mathrm{h}}$ hot water temperature at the generator inlet $\left({ }^{\circ} \mathrm{C}\right)$

$T_{\mathrm{N} 1}$ chilled water temperature at the evaporator inlet $\left({ }^{\circ} \mathrm{C}\right)$

$T_{\mathrm{N} 2}$ chilled water temperature at the evaporator outlet $\left({ }^{\circ} \mathrm{C}\right)$

$V_{2}$ volumetric flow at the expander inlet $\left(\mathrm{m}^{3} / \mathrm{s}\right)$

$V_{3}$ volumetric flow at the expander outlet $\left(\mathrm{m}^{3} / \mathrm{s}\right)$

VFR volumetric flow ratio 
$W_{\text {com }}$ compressor work input $(\mathrm{kW})$

$W_{\text {exp }}$ expander work output $(\mathrm{kW})$

$W_{\text {net }}$ net work output for ORC $(\mathrm{kW})$

$W_{\text {pump,w }}$ working fluid pump power consumption (kW)

WRm ratio of $W_{\text {net }}$ to $m_{\mathrm{p}}(\mathrm{kW} \mathrm{s} / \mathrm{kg})$

$\eta_{\text {com }}$ compressor isentropic efficiency

$\eta_{\text {exp }}$ expander isentropic efficiency

$\eta_{\mathrm{p}}$ organic Rankine cycle efficiency

$\eta_{\text {pump,w }}$ working fluid pump isentropic efficiency

Competing interests

The authors declare that they have no competing interests.

\section{Authors' contributions}

Xianbiao Bu carried out the establishment and analysis of numerical model. Lingbao Wang and Huashan Li participated in the data analysis and article writing. All authors read and approved the final manuscript.

\section{Acknowledgements}

The authors gratefully acknowledge the financial support from the National Hi-Tech Research and Development Program (863) of China (no. 2012AA053003), the National Natural Science Foundation of China (no. 51106161) and Guangdong Province and Chinese Academy of Sciences Comprehensive Strategic Cooperation Projects (2012B091100263).

\section{Author details}

${ }^{1}$ Key Laboratory of Renewable Energy and Gas Hydrate, Guangzhou Institute of Energy Conversion, Chinese Academy of Sciences, No.2, Nengyuan Rd, Wushan, Tianhe District, Guangzhou 510640, China. ${ }^{2}$ University of Chinese Academy of Sciences, Beijing 100049, China.

Received: 3 June 2013 Accepted: 31 July 2013

Published: 23 August 2013

\section{References}

Aphornratana S, Sriveerakul T (2010) Analysis of a combined Rankine-vapour-compression refrigeration cycle. Energy Convers Manage 51(12):2557-2564

Davis GW, Wu C (1997) Finite time analysis of a geothermal heat engine driven air conditioning system. Energy Convers Manage 38(3):263-268

Demierre J, Henchoz S, Favrat D (2012) Prototype of a thermally driven heat pump based on integrated organic Rankine cycles (ORC). Energy 4(1):10-17

Guo T, Wang HX, Zhang SJ (2011) Selection of working fluids for a novel low-temperature geothermally-powered ORC based cogeneration system. Energy Convers Manage 52:2384-2391

Hung TC, Wang SK, Kuo CH, Pei BS, Tsai KF (2010) A study of organic working fluids on system efficiency of an ORC using low-grade energy sources. Energy 35:1403-1411

Invernizzi C, lora P, Silva P (2007) Bottoming micro-Rankine cycles for micro-gas turbines. Appl Therm Eng 27:100-110

Kairouani L, Nehdi E (2006) Cooling performance and energy saving of a compression-absorption refrigeration system assisted by geothermal energy. Appl Therm Eng 26(2-3):288-294

Kececiler A, Ibrahim Acar H, Ayla D (2000) Thermodynamic analysis of the absorption refrigeration system with geothermal energy: an experimental study. Energy Convers Manage 41(1):37-48

Lakew AA, Bolland O (2010) Working fluids for low-temperature heat source. Appl Therm Eng 30:1262-1268

Lu ZS, Wang RZ, Xia ZZ (2013) Study of a novel solar adsorption cooling system and a solar absorption cooling system with new CPC collectors. Renew Energy 50:299-306

Lubis LI, Kanoglu M, Dincer I (2011) Thermodynamic analysis of a hybrid geothermal heat pump system. Geothermics 40(3):233-238

Lund JW, Freeston DH, Boyd TL (2005) Direct application of geothermal energy: 2005 worldwide review. Geothermics 34(6):691-727

Lund JW, Freeston DH, Boyd TL (2011) Direct utilization of geothermal energy 2010 worldwide review. Geothermics 40(3):159-180

Luo HL, Wang RZ, Dai YJ (2012) The effects of operation parameter on the performance of a solar-powered adsorption chiller. Appl Energy 87(10):3018-3022

Macchi E, Perdichizzi A (1981) Efficiency prediction for axial-flow turbines operating with nonconventional fluids. J Eng. for Power 103:718-724

Meunier F (1998) Solid sorption heat powered cycles for cooling and heat pumping applications. Appl Therm Eng 18(9-10):715-729

Qiu GQ (2012) Selection of working fluids for micro-CHP systems with ORC. Renew Energy 48:565-570

Rosiek S, Batlles FJ (2012) Shallow geothermal energy applied to a solar-assisted air-conditioning system in southern Spain: two-year experience. Appl Energy 100:267-276

Srikhirin P, Aphornratana S, Chungpaibulpatana S (2001) A review of absorption refrigeration technologies. Renew Sust Energy Rev 5(4):343-372 
Stijepovic MZ, Linke P, Papadopoulos Al, Grujic AS (2012) On the role of working fluid properties in organic Rankine cycle performance. Appl Therm Eng 36:406-413

Wang HL, Peterson R, Herron T (2011a) Design study of configurations on system COP for a combined ORC (organic Rankine cycle) and VCC (vapor compression cycle). Energy 36(8):4809-4820

Wang HL, Peterson R, Harada K (2011b) Performance of a combined organic Rankine cycle and vapor compression cycle for heat activated cooling. Energy 36(1):447-458

Wang EH, Zhang HG, Fan BY, Ouyang MG, Zhao Y, Mu QH (2011c) Study of working fluid selection of organic Rankine cycle (ORC) for engine waste heat recovery. Energy 36:3406-3418

Wang ZQ, Zhou NJ, Guo J, Wang XY (2012) Fluid selection and parametric optimization of organic Rankine cycle using low temperature waste heat. Energy 40:107-115

Wang XL, Bierwirth A, Christ A (2013) Application of geothermal absorption air-conditioning system: a case study Appl Therm Eng 50(1):71-80

doi:10.1186/2195-9706-1-2

Cite this article as: Bu et al:: Performance analysis and working fluid selection for geothermal energy-powered organic Rankine-vapor compression air conditioning. Geothermal Energy 2013 1:2.

\section{Submit your manuscript to a SpringerOpen ${ }^{\circ}$ journal and benefit from:}

- Convenient online submission

Rigorous peer review

- Immediate publication on acceptance

- Open access: articles freely available online

- High visibility within the field

- Retaining the copyright to your article

Submit your next manuscript at $\boldsymbol{\sim}$ springeropen.com 